\title{
BMJ Open Development of entrustable professional activities for residents rotating nephrology department in a Japanese university hospital: a Delphi study
}

\author{
Akihito Tanaka (D) ,1,2 Takeshi Kondo (D) ,' Yuka Urushibara-Miyachi, ${ }^{3}$ \\ Shoichi Maruyama, ${ }^{4}$ Hiroshi Nishigori ${ }^{1,5}$
}

To cite: Tanaka A, Kondo T, Urushibara-Miyachi Y, et al. Development of entrustable professional activities for residents rotating nephrology department in a Japanese university hospital: a Delphi study. BMJ Open 2021;11:e047923. doi:10.1136/ bmjopen-2020-047923

- Prepublication history for this paper is available online. To view these files, please visit the journal online (http://dx.doi. org/10.1136/bmjopen-2020 047923).

Received 12 December 2020 Accepted 21 July 2021

Check for updates

(c) Author(s) (or their employer(s)) 2021. Re-use permitted under CC BY-NC. No commercial re-use. See rights and permissions. Published by BMJ.

For numbered affiliations see end of article.

Correspondence to

Dr Akihito Tanaka;

tanaka17@med.nagoya-u.ac.jp

\section{ABSTRACT}

Objectives Training strategies regarding entrustable professional activities (EPAs) vary from country to country; one such strategy is for residents. However, there are no reports of EPAs developed for residents who rotate to the nephrology departments. We aimed to construct such EPAs, which could be generalised to other institutions. Design Purposive design and a modified Delphi method to build consensus.

Setting The department of nephrology in a university hospital in Aichi Prefecture, Japan.

Participants Based on the attainment goals used in our department, an initial list was developed within the research group. The expert panel included 25 nephrologists from our affiliate hospital. Responses were based on a 5-point method and agreement was reached if both (A) and (B) were met: (A) mean $\geq 4$ with a $S D<1$; (B) more than $75 \%$ of respondents rated the item 4 or more. With agreement, the item was left for the next round. This round was repeated.

Results An initial list of 11 items was developed; after three Delphi rounds and revisions, eight items remained that were then established as the final EPAs. These items can serve as a list of goals to be reached by residents who rotate to the department of nephrology. The results indicated that most of the experts believed residents should be able to perform tasks deemed necessary or urgent for all physicians, such as those that deal with hyperkalaemia and heart failure.

Conclusions The concept of EPAs enabled us to develop goals and evaluation criteria for residents' training in nephrology. This study can serve as a springboard for future discussions and contribute to the development of resident education in nephrology.

\section{BACKGROUND}

In recent years, medical education has shifted to competency-based medical education (CBME), ${ }^{1}$ which is highly significant as it has created a consistent flow of underand post-graduate and continuing medical education, and has made medical educators
Strengths and limitations of this study

- This is a first report about entrustable professional activities (EPAs) in nephrology for residency training established by modified Delphi study.

- All experts in our panel responded to all rounds of the study.

- All experts in our panel were experienced in clinical work and residency training because our institution was a university hospital.

- This is our institution's only EPAs and it was created at a single institution.

- We have not yet been able to link this EPA to the target competencies.

aware of the need for professionalism and communication. As in other countries, CBME is currently being applied in Japan. Specifically, CBME in Japan is based on nine competencies: professionalism including medical ethics, medical knowledge and problemsolving ability, practical skills and patient care, communication skills, practice of teambased healthcare, management of quality of care and patient safety, medical practice in society, scientific inquiry, and attitudes for life-long and collaborative learning. Residency training is designed to achieve these competencies. ${ }^{2}$ However, various problems have been identified with CBME, such as the subitems of competencies being too detailed, difficulty in adapting them to the context of the field and inadequate quality of assessment tools (eg, they do not consider the level of competence desired for the learner). ${ }^{3}$ These challenges may represent difficulties at the stage of translating competencies into clinical education practice. ${ }^{4}$ Therefore, in recent years, the concept of entrustable professional activities (EPAs) has expanded in medical 
education to bridge the potential gap between the theory of competency-based education and educational practice. ${ }^{5-7}$ An EPA is 'a unit of work that can be entrusted to a fully competent learner in a trustworthy manner'. This concept is useful because it provides guidance regarding the tasks that can be entrusted to a learner, can assess multiple qualities and abilities of a learner, and is consistent with the sense of the physician in the field. ${ }^{8}$ Furthermore, EPA has the following advantages: it does not require a specific amount of time such as a written test; it is observable and measurable and consistent with the judgement that the physician can be entrusted with the task; it can be assessed in consideration of the level of instruction; and it can be done by the physician themselves. ${ }^{9-11}$

In Japan, postgraduate training is called residency training, which means there is a 2-year period of initial training after completing 6years of undergraduate medical education and obtaining a medical license. During this residency training, residents rotate through various departments and acquire a wide range of basic knowledge and skills before advancing to a specialty department. During the residency training at our Nagoya University Hospital, 6 months of training in internal medicine is required and residents can choose nephrology from a range of its subspecialties.

Nagoya University Hospital has 1032 beds including 14 beds in department of nephrology for admitted patients. At our institution, there are approximately 15 residents each year. Nephrology-related duties include the haemodialysis initiation of about 50 cases per year, which are then referred to a nearby physician. Approximately 70 patients per month come to our hospital for peritoneal dialysis treatment. Kidney transplantation is also performed in our hospital.

The majority of residents, but not all, choose to rotate nephrology in Nagoya University Hospital. For example, a resident who wants to become a geriatrician would rotate to strengthen his or her knowledge of nephrology. Therefore, we need to set up EPAs for these residents. Some reports have incorporated EPAs as part of nephrology specialty or fellowship training ${ }^{12-14}$; however, there are no reports of EPAs in nephrology for residency training that asks all the medical school graduates to gain experience of various specialties. Based on this gap in the literature, in this research, we aimed to create EPAs for residents in the department of nephrology at our hospital, which can be transferrable to other institutions. We believe that resulting EPAs of this study can support self-directed management of rotational trainings of residents not only who wish to but also do not necessarily become nephrologists. Ultimately, our aim is to map EPAs to the available competencies and to create goals and milestones for residents to reach. For this reason, we thought it was important to create EPAs first for residents to rotate the department of nephrology.

\section{METHODS}

\section{Consensus-building methods}

We adopted the modified Delphi method for this study. The Delphi method is a technique for systematically building consensus on a subject in a group of experts who are familiar with the subject, with anonymous feedback from experts and repeated revisions based on that feedback. In contrast to the classical Delphi method, in which consensus is formed through repeated expert feedback for creating the initial list, the modified Delphi method uses a precreated list to reach consensus on the list. In the present study, the modified Delphi method ${ }^{15}$ was adopted to create the initial list in the research group by referring to the general and behavioural goals reviewed annually in the Department of Nephrology at the Nagoya University Hospital.

\section{Creating the initial list}

An initial list was created by members of the research team through discussions on general goals and behavioural objectives that had been reviewed annually in the Department of Nephrology at the Nagoya University Hospital. These members included those involved in the nephrology department's review of general and behavioural goals and a medical education specialist. It has been reported that the development of the EPA would not be effective without the participation of those skilled in it, ${ }^{16}$ and the members of the current study group included members who were familiar with the development of the EPA.

\section{Expert panel selection and questionnaire responses}

From October 2019 to March 2020, an expert panel of 25 clinical university staff specialising in nephrology was selected by purposive sampling. While no consensus has been reached on the most appropriate number of experts to be included in the panel, previous studies have generally asked for at least 20 experts to participate in order to achieve sufficient reliability. ${ }^{17}$ Since the average response rate for previous Delphi studies has been around $80 \%,{ }^{18}$ we targeted to recruit 25 experts for this study. A questionnaire created using Google Form was administered to the panel. They were asked to rate items, on a 5-point Likert scale, to include in each goal, keeping in mind how far they would like residents to be at the end of their 4-week nephrology rotations. ( $1=$ absolutely should be excluded, $2=$ should be excluded, $3=$ neither, $4=$ should be included, $5=$ should definitely be included). If there were any items to be added, they were asked to be added to the list.

The data were collected, and the list was compiled, leaving a list of targets to be reached with a certain amount of agreement from the expert panel. It was decided to leave the agreed-upon targets for the next round, after a discussion within the research group. After discussion, the research group decided to leave the items that were agreed on in the next round. After the second Delphi round for the revised list, its data collection, analysis and editing were performed. The Delphi round, data 
collection, analysis and editing list were repeated. The round ended with a consensus on all items.

\section{Our consensus standard}

EPA is a relatively new concept to Japanese medical teachers. We expected that the university faculty we recruited would be familiar with the professional work required of residents rotating in the department of nephrology, but would not necessarily have a sufficient understanding of what EPAs are. For such faculty, discussing competencies that are not always observable would be even more problematic than identifying EPAs that are observable as part of their practice. As Ten Cate et al point out, ${ }^{16}$ when validating EPAs using the Delphi method, participants' lack of understanding of what EPAs are can put them at risk of being flawed, and flawed EPA items that were not excluded as a result of their insufficient understanding are rarely modified again. Therefore, this study aimed to first focus on translating the professional work into EPAs, in order to promote a proper understanding of EPAs among faculty through research. In addition, by stricter consensus criteria, we ensured that only those items that were rated as definitely worthy of inclusion by even though experts unfamiliar with the concept of EPAs would remain. Then, we considered that the experts reached an agreement on items when responses obtained both (A) and (B).

A. The mean is $\geq 4$ and the $\mathrm{SD}$ is $<1$.

B. Seventy-five per cent or more of experts rate the item as 4 or 5 .

\section{Patient and public involvement}

Patients were not involved.

\section{RESULTS}

\section{Delphi response rate and panel members}

The panel members included 25 medical doctors and all participants completed all three rounds. The participants' demographics and characteristics are shown in table 1 .

\section{Delphi round}

The research team developed an initial list of items that they considered to be work based and feasible for residents, based on the general and behavioural goals reviewed annually by the department of nephrology. There were 11 items in the initial list; table 2 shows the results of Delphi round 1 on the list.

Basic skills-such as making a problem list and presenting at a conference-remained for the next

\begin{tabular}{ll}
\hline Table 1 Characteristics of the expert panel $(\mathrm{n}=25)$ \\
\hline Parameter \\
\hline Female (\%) & 20.0 \\
\hline Working experience as a physician (year) & $15.7 \pm 7.4$ \\
\hline Faculty (\%) & 64.0 \\
\hline
\end{tabular}

round, while items such as dietary orders, lifestyle guidance and writing a referral letter were limited to round 1. Additional items were proposed, such as the classification of chronic kidney disease (CKD), initial response to fever in a patient who takes steroids, blood pressure control in hospitalised patients and explanation of renal replacement therapy in CKD patients. Items 8 and 9 were modified with the comment that they do not need to be limited to the emergency room. Items for which the scores did not meet the consensus criteria were removed and a modified list of items is shown in table 3 , along with the Delphi round 2 results for those items.

Of the four new items added, two items-item 12, classification of CKD and 13, initial response to fever in patients on steroids-remained; however, the other two items-item 14, blood pressure control in hospitalised patients and 15, renal replacement therapy explanation to patients with CKD-did not remain. Two items, number 8 and 9 , were revised according to the comments, suggesting that it would be better to be able to determine the necessity of dialysis. The new list of attainment objectives was created based on those items and the results of Delphi round 3 are shown in table 4 .

All of these items ultimately remained in the scale, and there were no comments that required a change in content. Therefore, this was used as the final list of goals for residents who rotate to the Department of nephrology.

\section{DISCUSSION}

We developed EPAs for residents rotating to the department of nephrology. This study is novel in that it creates consensus among supervisors for resident's training while on rotation in the nephrology department; to the best of our knowledge, this has not been previously reported.

Regarding nephrology, there are very limited examples of training using the concepts of EPA. In the USA, previous studies have applied the concept of EPA to nephrology as a subspecialty of internal medicine ${ }^{12}$ and to evaluate the usefulness of providing outpatient nephrology training as part of nephrology fellowship training. ${ }^{13}$ However, the EPAs in these reports have been for specialty or fellowship trainings. Furthermore, a report in Canada is in the process of creating incremental EPAs, as training progresses. ${ }^{14}$ However, in Canada, students decide on a department on graduation and do not rotate through non-required departments. Furthermore, the report is a national-level study and does not consider the circumstances of each hospital. It reports an EPA such as maximum common denominator with a different scope of coverage in practice than our study. Therefore, there are currently no reports defining EPAs for rotating residents in the nephrology department.

As the target group in this study was non-specialising residents rotating to the department of nephrology, items that were necessary for all physicians (eg, making a problem list and presentation at a conference) rather than items specific to nephrology received high scores 
Table 2 Results of round 1 in modified Delphi method

\section{Items of EPA in Delphi round 1}

\section{Score (average \pm SD)}

$4.84 \pm 0.37$

Per cent agree (4 or 5)

1. Assessment of patients' status performing medical interview and physical examination, and writing medical records with problem lists including kidney conditions (eg, AKI, CKD, RPGN, nephrotic syndrome, chronic glomerulonephritis), when patients with renal impairment.

2. Ordering (after checking with the senior physician) the examinations $4.56 \pm 0.58$ (eg, CT of the abdominal, echocardiography, urinalysis), which are necessary to determine the cause of the impairment when patients with renal impairment are admitted to the hospital.

\section{Presentation at the conference about the reason for admission, the current situation and the treatment plan when patients with renal impairment are admitted to the hospital.}

4. Identification of patients' medication and discussion with the senior physician to determine whether the medicines need to be reduced or discontinued, depending on renal function when patients with renal impairment are admitted to the hospital.

\section{Ordering diet according to their kidney status when patients with} CKD are admitted to the hospital. If necessary (especially in the case of hyperkalaemia), dietary instructions should also be given.

6. Medical interview about life history, diet, exercise and preferences and considering whether there are any interventions should be made when patients with CKD are admitted to the hospital. If there are, pointing them out.

\section{Listening to the shunt murmur of the haemodialysis patient and} determining if there is an obstruction.

8. Initial response (eg, calcium gluconate, GI therapy, sodium bicarbonate, cation exchange resin) for hyperkalaemia when called from emergency room.

\section{Initial response (eg, diuretics, nitrates, NPPV when necessary) for} heart failure due to renal failure and fluid overload when called from emergency room.

10. Writing a draft referral letter for patients with CKD or dialysis who are being transferred to other hospitals.

\section{Explanation of the expected benefits and adverse effects that should be of concern when patients need steroid treatment.}

\section{Items}

1.

2.

5.

8.

9.

11.

Others.

$4.80 \pm 0.50$

96.0

$4.16 \pm 0.80$

76.0

96.0

100.0

$3.88 \pm 0.78 \quad 64.0$

$3.88 \pm 0.78$

64.0

$4.04 \pm 0.98$

72.0

$4.64 \pm 0.49$

100.0

$4.24 \pm 0.66$

88.0

$3.64 \pm 1.11$

60.0

$4.20 \pm 0.71$

84.0

Comments

CKD classification should be performed.

Ordering may be too difficult.

Initial residents are enough to follow the guidelines.

It may be too difficult. There is a need to consult a senior physician. The word 'emergency room' is not necessary.

It may be too difficult. There is a need to consult a senior physician. The word 'emergency room' is not necessary.

It may be too difficult.

'Initial response for fever in patients with immunosuppression therapy'

'Management for hypertension in hospitalised patients' 'Explanation for RRT in hospitalised patients' should be added.

AKI, acute kidney injury; CKD, chronic kidney disease; EPA, entrustable professional activity; Gl, glucose-insulin; NPPV, non-invasive positive pressure ventilation; RPGN, rapidly progressive glomerulonephritis; RRT, renal replacement therapy. 
Table 3 Results of round 2 in modified Delphi method

Items of EPA in Delphi round 2

Score (average \pm SD)

Per cent agree (4 or 5$)$

1. Assessment of patients' status performing medical interview and physical

$4.84 \pm 0.37$

100.0

examination, and writing medical records with problem lists including

kidney conditions (eg, AKI, CKD, RPGN, nephrotic syndrome, chronic

glomerulonephritis), when patients with renal impairment are admitted to the

hospital.

2. Planning the examinations (eg, abdominal CT, echocardiography, urinalysis) $4.52 \pm 0.65$

92.0

which are necessary to determine the cause of the impairment when patients

with renal impairment are admitted to the hospital.

$\begin{array}{ll}\text { 3.Presentation at the conference about the reason for admission, the current } & 4.68 \pm 0.56 \\ \text { situation, and the treatment plan when patients with renal impairment are } & 96.0\end{array}$

admitted to the hospital.

4. Identification of patients' medication and discussion with the senior

$4.24 \pm 0.72$

84.0

physician to determine whether the medicines need to be reduced or

discontinued, depending on renal function when patients with renal

impairment are admitted to the hospital.

\begin{tabular}{l}
$\begin{array}{l}\text { 8. Planning initial response (eg, calcium gluconate, Gl therapy, sodium } \\
\text { bicarbonate, cation exchange resin) for hyperkalaemia. }\end{array}$ \\
\hline
\end{tabular}

9. Planning initial response (eg, diuretics, nitrates, NPPV when necessary) for $\quad 4.04 \pm 0.68$

heart failure due to renal failure and fluid overload.

\begin{tabular}{|c|c|c|}
\hline $\begin{array}{l}\text { 11. Explanation of the expected benefits and adverse effects that should be of } \\
\text { concern when patients need steroid treatment. }\end{array}$ & $4.00 \pm 0.76$ & 72.0 \\
\hline 12. Classification of CKD (cause and stage). & $4.28 \pm 0.79$ & 80.0 \\
\hline 13. Initial response for fever in patients with immunosuppression therapy. & $4.08 \pm 0.70$ & 80.0 \\
\hline $\begin{array}{l}\text { 14. Management for hypertension in hospitalised patients with CKD assessing } \\
\text { their complication and target of treatment. }\end{array}$ & $3.84 \pm 0.80$ & 68.0 \\
\hline $\begin{array}{l}\text { 15. Explanation for RRT and the characteristics in hospitalised patients with } \\
\text { CKD. }\end{array}$ & $3.80 \pm 0.87$ & 60.0 \\
\hline Items & \multicolumn{2}{|l|}{ Comments } \\
\hline 8. & \multicolumn{2}{|c|}{$\begin{array}{l}\text { It is necessary. Including assessment for the necessity } \\
\text { of dialysis therapy is better. }\end{array}$} \\
\hline 9. & \multicolumn{2}{|c|}{$\begin{array}{l}\text { Including assessment for the necessity of dialysis } \\
\text { therapy is better. }\end{array}$} \\
\hline
\end{tabular}

AKI, acute kidney injury; CKD, chronic kidney disease; EPA, entrustable professional activity; GI, glucose-insulin; NPPV, non-invasive positive pressure ventilation; RPGN, rapidly progressive glomerulonephritis; RRT, renal replacement therapy.

and remained on the list of EPAs. Conversely, items that were highly specific to nephrology (eg, explanation of renal replacement therapy, ordering meals and lifestyle guidance) were excluded. As residents were not set on becoming nephrologists, it is likely that the items that were useful to them tended to get higher scores, even when they chose other specialties. Alternatively, it is possible that they had just become physicians and that rudimentary and basic content was more likely to remain on the list. Furthermore, the characteristics of nephrology may be related to the results. Physicians in nephrology are often consulted when patients who are admitted to other departments show deterioration of their renal function. To determine the cause of the deterioration of renal function, it is necessary to take an entire medical history and examination of the patient, identify the problem appropriately, and decide on a course of action. Nephrologists need to understand the complete picture of a patient's health.

Other conditions that required urgent attention (eg, hyperkalaemia and heart failure) were also given high scores. These conditions were also considered useful to the residents because they could be encountered urgently in the future, even if they chose a different department, and because they required prompt attention. Based on these results, we believe that the majority of the expert panel were of the opinion that residents should be able to perform tasks deemed necessary or urgent for all physicians. In other words, the expert panel understood the level of the residents and set EPAs that were appropriate for them, as it was considered important for the expert panel to understand the process of creating the EPA. ${ }^{16}$ Therefore, EPAs may be characterised by setting the goals necessary for the work, taking into account the level of 
Table 4 Results of round 3 in modified Delphi method

\section{Items of EPA in Delphi round 3}

Score (average \pm SD)

Per cent agree (4 or 5$)$

1. Assessment of patients' status performing medical interview and physical examination, and writing medical records with problem lists $4.88 \pm 0.33 \quad 100.0$ including kidney conditions (eg, AKI, CKD, RPGN, nephrotic syndrome, chronic glomerulonephritis), when patients with renal impairment are admitted to the hospital.

2. Planning the examinations (eg, abdominal CT, echocardiography, $4.64 \pm 0.49$ 100.0 urinalysis) which are necessary to determine the cause of the impairment when patients with renal impairment are admitted to the hospital.

\section{Presentation at the conference about the reason for admission, the current situation, and the treatment plan when patients with renal impairment are admitted to the hospital.}

4. Identification of patients' medication and discussion with the senior physician to determine whether the medicines need to be reduced or discontinued, depending on renal function when patients with renal impairment are admitted to the hospital.

\begin{tabular}{|c|c|c|}
\hline 8. Planning initial response for hyperkalaemia. & $4.64 \pm 0.57$ & 96.0 \\
\hline $\begin{array}{l}\text { 9. Planning initial response for heart failure due to renal failure and fluid } \\
\text { overload. }\end{array}$ & $4.24 \pm 0.66$ & 96.0 \\
\hline 12. Classification of CKD (cause and stage). & $4.60 \pm 0.50$ & 100.0 \\
\hline 13. Initial response for fever in patients with immunosuppression therapy. & $4.00 \pm 0.82$ & 84.0 \\
\hline Items & Comments & \\
\hline 2. & It is necessary. & \\
\hline 3. & It is necessary. & \\
\hline 8. & $\begin{array}{l}\text { It is necessary. } \\
\text { residents who ro }\end{array}$ & $\begin{array}{l}\text { the greatest for } \\
\text { hrology. }\end{array}$ \\
\hline
\end{tabular}

AKI, acute kidney injury; CKD, chronic kidney disease; EPA, entrustable professional activity; RPGN, rapidly progressive glomerulonephritis.;

the learner, if the expert panellists create EPAs with a good understanding.

Furthermore, construction of EPAs also helps clarify the position of non-mandatory departments in a rotation system. In addition, clarification of what can be learnt in the rotation can assist residents in making decisions about rotations in non-mandatory departments. ${ }^{19}$

\section{STRENGTH AND LIMITATIONS}

One of the strengths of this study is that all expert panellists responded to all rounds of the study. Second, all physicians were experienced in clinical work and residency training because our institution was a university hospital. However, there are limitations to this study. First, this is our institution's only EPAs and it was created at a single institution. Departments that perform procedures such as vascular access surgery may vary by institution (eg, departments of nephrology, urology or vascular surgery may be responsible for the procedure). Hence, we believe that each hospital needs to localise its own EPA. In terms of localisation, the creation of EPAs at a single facility could be an advantage since all expert panellists know actual state of the facility, although it is a limitation in terms of generalisation. Second, we have not yet been able to link this EPA to the target competencies. In the future, we will use these EPAs in real settings to evaluate how they correspond to the competencies. Third, the study did not adequately deal with procedures such as insertion of central venous catheters for haemodialysis, which would be difficult for a trainee to perform independently but which could be learnt by observation. We believe this limitation is due to the fact that we designed our assessment and education using the concept of EPA, and electrolyte-related content may have been similarly affected.

\section{CONCLUSIONS}

We believe that this report will serve as a springboard for future discussions and contribute to the development of resident education in nephrology. In addition, the results of this study will be useful for the education of residents in other countries that have rotational clinical training programmes.

Author affiliations

${ }^{1}$ Center for Postgraduate Clinical Training and Career Development, Nagoya University Hospital, Nagoya, Japan

${ }^{2}$ Department of Nephrology, Nagoya University Hospital, Nagoya, Japan

${ }^{3}$ Faculty of Medicine, Kyoto University, Kyoto, Japan

${ }^{4}$ Department of Nephrology, Nagoya University Graduate School of Medicine, Nagoya, Aichi, Japan 
${ }^{5}$ Center for Medical Education, Nagoya University Graduate School of Medicine, Nagoya, Aichi, Japan

Contributors AT wrote the manuscript. AT, TK, YU-M, SM and HN designed and performed this study. SM and HN supervised the study.

Funding The authors have not declared a specific grant for this research from any funding agency in the public, commercial or not-for-profit sectors.

Competing interests None declared.

Patient consent for publication Not required.

Ethics approval Ethical approval was provided by the institutional review board of the Nagoya University Hospital (approval number: 2019-0257). Consent from participants was obtained in the form of opt-out.

Provenance and peer review Not commissioned; externally peer reviewed.

Data availability statement Data are available upon reasonable request.

Open access This is an open access article distributed in accordance with the Creative Commons Attribution Non Commercial (CC BY-NC 4.0) license, which permits others to distribute, remix, adapt, build upon this work non-commercially, and license their derivative works on different terms, provided the original work is properly cited, appropriate credit is given, any changes made indicated, and the use is non-commercial. See: http://creativecommons.org/licenses/by-nc/4.0/.

ORCID iDs

Akihito Tanaka http://orcid.org/0000-0001-8866-5901

Takeshi Kondo http://orcid.org/0000-0002-3307-671X

\section{REFERENCES}

1 Kavic MS. Competency and the six core competencies. JSLS 2002;6:95-7.

2 Ministry of Health, Labor and Welfare. Ishi-Rinsho-Kenshu Guideline-2020. Available: https://www.mhlw.go.jp/stf/newpage 03924.html [Accessed 29 Aug 2020].

3 Pangaro L, ten Cate O, Cate OT. Frameworks for learner assessment in medicine: AMEE guide No. 78. Med Teach 2013;35:e1197-210.
4 ten Cate O, Scheele F. Competency-based postgraduate training: can we bridge the gap between theory and clinical practice? Acad Med 2007;82:542-7.

5 Glass JM. Competency based training is a framework for incompetence. BMJ 2014;348:g2909.

6 Talbot M. Monkey see, monkey do: a critique of the competency model in graduate medical education. Med Educ 2004;38:587-92.

7 Ten Cate O, Cate OT. Am last page: what entrustable professional activities add to a competency-based curriculum. Acad Med 2014;89:691.

8 ten Cate O, Cate OT. Entrustability of professional activities and competency-based training. Med Educ 2005;39:1176-7.

9 Shorey S, Lau TC, Lau ST, et al. Entrustable professional activities in health care education: a scoping review. Med Educ 2019;53:766-77.

10 Meyer EG, Chen HC, Uijtdehaage S, et al. Scoping review of entrustable professional activities in undergraduate medical education. Acad Med 2019;94:1040-9.

11 Oversight Working Network, Rose S, Fix OK, et al. Entrustable professional activities for gastroenterology fellowship training. Gastrointest Endosc 2014;80:16-27.

12 Yuan CM, Prince LK, Oliver JD, et al. Implementation of nephrology subspecialty curricular milestones. Am J Kidney Dis 2015;66:15-22.

13 Yuan CM, Prince LK, Zwettler AJ, et al. Assessing achievement in nephrology training: using clinic chart audits to quantitatively screen competency. Am J Kidney Dis 2014;64:737-43.

14 Pinsk M, Karpinski J, Carlisle E. Introduction of competence by design to Canadian nephrology postgraduate training. Can J Kidney Health Dis 2018;5:205435811878697.

15 Hasson F, Keeney S, McKenna H. Research guidelines for the Delphi survey technique. J Adv Nurs 2000;32:1008-15.

16 Ten Cate O, Chen HC, Hoff RG, et al. Curriculum development for the workplace using entrustable professional activities (EPAs): AMEE guide No. 99. Med Teach 2015;37:983-1002.

17 Dunn WR, Hamilton DD, Harden RM. Techniques of identifying competencies needed of doctors. Med Teach 1985;7:15-25.

18 Dielissen P, Verdonk P, Bottema B, et al. Expert consensus on gender criteria for assessment in medical communication education. Patient Educ Couns 2012;88:189-95.

19 University of Waterloo. Self-Directed learning: a four-step process. Available: https://uwaterloo.ca/centre-for-teaching-excellence/ teaching-resources/teaching-tips/tips-students/self-directedlearning/self-directed-learning-four-step-process [Accessed 29 Aug 2020]. 